\title{
Evaluation of Traditional and Strategic Human Resource Management
}

\author{
Baocai FAN ${ }^{1, a}$, Hong WANG ${ }^{1, b}$ * \\ ${ }^{1}$ Business School, Sichuan University, Chengdu, Sichuan, P.R. China \\ a1147771505@qq.com, b781617414@qq.com
}

\begin{abstract}
Keywords: Human Resource Management;SHRM;Evaluation
Abstract. With the development of human resource theories, it allows management to do HR practice in a more flexible and effective way. Meanwhile, human resource management experiences a procedure of evolution - as a brain new type of HRM, Strategic Human Resource Management which is the result of the evolution has brough to the organization's attention.. In this study, the researcher tried to explore which one is more suitable for firms between traditional HRM and strategic HRM.The paper involved an analysis of today's business environment, a description of the characteristic of SHRM, and also showed the reader the fundamental of reaching SHRM. After these, two opposite and specific examples were presented in order to bring readers a further thinking on this professional field.The results of the study revealed that the balance of using traditional HRM and strategic HRM could be important to organizations.
\end{abstract}

\section{Introduction}

It can easily be seen that Human Resource Management plays a significant role in modern society. Contrary to this, HRM theory is improving constantly as time goes on, and there is a divergence on traditional and strategic HRM - which one nowadays is more appropriate for firms. This issue is worth discussing because of all employing organizations consider about capabilities and potential that employees offer them in order to achieve success and survive into a long healthy term[1] .

The traditional meaning of HRM has been defined as processes and procedures that organizations use for managing people on recruitment, development, benefit and overall organization climate[2]. According to CIPD, the concept of strategic HRM can be spoke as a human resource management approach to provide a strategic configuration to encourage long-term business goals, which is also related to future needs and macro-concerns. In order to explore which is more suitable for firms in today's business environment, analysis and comparison are used in this research. This knowledge will help companies to advance its own business structure and survive in competition[3].

\section{Literature Review}

Sustainability is an essential element of the business strategy in today's business environment [4]. In order to make sustainability contribute, culture change is required, which depends on whether employees can profoundly, uniformly and logically combine their own efforts with sustainability goals or not[5].

According to a research report by Society for Human Resource Management, BSR and Aurosoorya [6], even though sustainability is not a necessary point for HR, it is an issue that HR should seriously consider. This issue is about that people affect the corporate culture and company's behavior. And also, it affects the human resource system, the interaction on customers, the messaging that companies use in recruiting. And it changes organization to consider about how companies engage and retain employees, how they train employees and how they interact with customers, as same as the corporate brand and value orientation. Because of these reasons, HR must highly attach importance to the organization's sustainability activities. Many entrepreneurs find that the HR profession should seize the opportunity to demonstrate leadership on this critical strategic interest, because they witness the lack of leadership around sustainability. Whereas, they did not realize it is fundamental that HR serves on the company's owner for sustainability on an uninterrupted basis. No matter it is the owner or not, HR 
has responsibility to ensure guidelines, encourage employee communications, exploit strategy, develop a training system and take part in determining measurement for sustainability[7].

As the analysis presented above and the definition of traditional HRM and strategic HRM presented in introduction, it is clear to see the necessity of SHRM, and to some extent, it also give us an explanation on the increase of SHRM as a field of study universally. The dimension of the impact of HR practices on organizational performance is the basic principle of high maturity organizations[8]. The core of successful SHRM is to ensure the potent combination of human resource systems and integration which consists of organization structures and strategies. Without their combination, SHRM means nothing but an ornament[9]. For those scholars and entrepreneurs, SHRM not only includes the strategic dimension, but also includes following three aspects.

As can be seen from Figure 1, it means that, while HRM is concerned with the activities presented at the horizontal integration, SHRM is thinking more about the activities presented at the vertical level, in order to make sure that these "fit" with the strategic orientation in which the organization is moving. Figure 1 (see below) helps to give an example and show the construct of vertical and horizontal integration.Another way to see the key area of SHRM is to make a connection of SHRM and the "resource-based view of the firm"[10]. This view presents that, organizations can be conceptualized as consisting of a set of tangible and organizational success. Organization's resources consist of its capitals, performance, knowledge, processes, particularities and information, from a SHRM point of view, the performance and knowledge associated with employees are both developed and used to create new capabilities that boost organizational success. This can be shown as Fig.1.

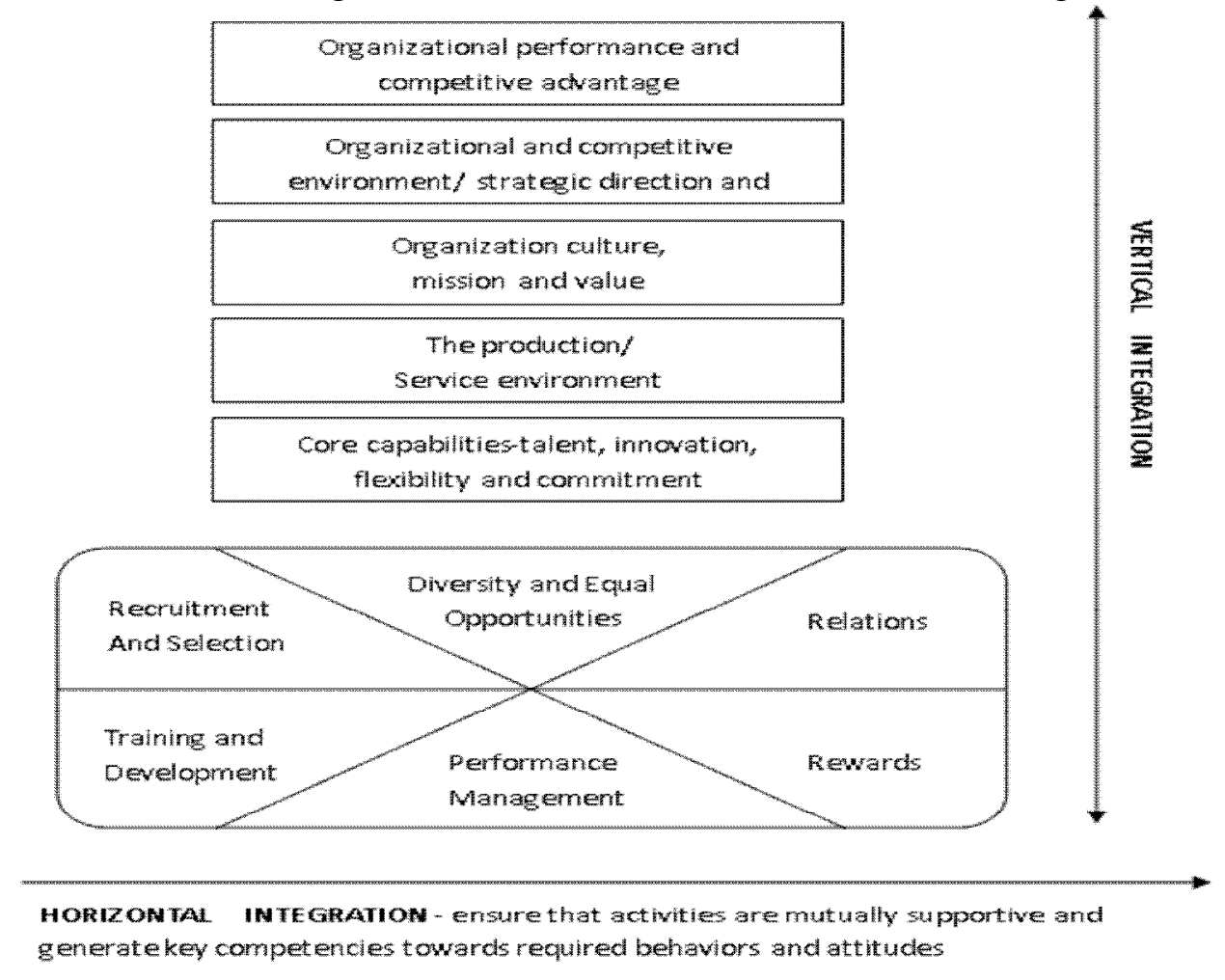

Fig.1

The third way of understanding SHRM is to read it in the field of strategic choice. Strategic choice is about making critical decisions in the emphasis area of managing people, and management should consider on whether to: use an individualist approach to communicate with employees or to transact with trade unions; give employees compensation on virtue, capability and latent force, or pay them base on what they do and how long they spend on.;make use of experts or those that are appropriate ;base 
the employees' need of growth and self-actualization;develop more suitable and creative polices and practices or use a "one size fits all" method to develop HR practices .

In order to find out a pathway to reach SHRM, it is necessary to understand the difference between high commitment SHRM and low commitment SHRM.In high commitment SHRM, the "best practice" model is followed by the employer. A close relationship with employees is required as a significant reason which makes employee loyalty to the organization. Opportunities for personal growth and career development which is setting in employment make it possible to continue covering all sorts of tasks[11]. In low commitment SHRM, HR follows "hire and fire" principles when recruitment is immediately needed. Employees are hired to engage in a low value work which does not need much training. And the relationship with employees is not close and flexible at all[12].

\section{Case Study}

In order to survive in today's business environment, Infosys had to make a change in the way they did business. But such a great change caused their infrastructure of employees a negative effect. They make an effort on corporate strategy and employees are included in this effort by making changes in working atmospheres and work patterns.. Contrary, employees were still grouchy because of the dramatic increase in the numbers of hired employees and distance between realities and expectations. Further to this, there were a few growth opportunities and chances of expressing creative solutions for employees due to Infosys focused more on its corporate strategy. Therefore, the employees felt themselves worthless in the work. Infosys tried to tip the balance. More efforts were made to desist from the dissatisfaction. For instance, they implemented volunteer options to make a more fascinating work environments than before, they put more Infosys culture studies in staff training for educating, etc. Contrary to their expectation, the situation became worse. Management could not realize that what is the main reason caused this issue and they did not know where to start engaging. Hence, the issue continued growing with the size of Infosys.

Even though a lot of efforts had been done, management could hardly rectify the position, so they put more concern into business strategy rather than this issue. Whereas, Infosys's business strategy such as variable pay and promotion policy leaded a great deal of employees being without knowledge of future prospects. Furthermore to this, there was not any statement for these new policies or their affection to the employees.Financially, Infosys did increase revenue by performing these corporate strategies, but maybe the growth was too large for them to operate. Management should pay more attention to human resource managers' practice to make sure they understand the need for recruitment and need of changing policies as a statement for increased employees. Management showed little consideration for the voice of employees, but rather cared too much on business strategies. The employees could not find themselves any value, and at the same time, the dimission rate was so high that made them feel equally disposable.

\section{Conclusion}

This paper reveals the choice between traditional HRM and strategic HRM in today's business environment, it can be expected, there is an inevitable trend of organization to receive a long-term benefit by using strategic human resource management.From the examples presented above, on one hand, Mayo showed us an efficient way to get a successful achievement by using SHRM, and proved the necessary of SHRM. On the other hand, management should consider more about the balance between traditional HRM and strategic HRM in the case of Infosys. It gave us a cautionary lesson that traditional HRM cannot be ignored by organization, because of its irreplaceable effects on helping organization growth.However, there are still many aspects worth discovering in this specific issue. It would be interesting if the different sizes of organization was considered in this paper. It is beyond doubt that more studies are going to be done in the field of SHRM, in order to help organizations to advance their business structure and survive in competition. 


\section{References}

[1] Aaker D A. Managing brand equity: Capitalizing on the value of a brand name [M]. Free press New York, 1991.

[2] Siomkos G J, Malliaris P G. Consumer Response to Company Communications during a Product Harm Crisis [J]. Journal of Applied Business Research, 1992, 8(Fall): 59.

[3] Mowe J.C. The time and outcome valuation model: Implications for understanding reactance and risky choices in consumer decision making [J]. Advances in consumer research, 1992. 19: 182-189.

[4] Sitkin S B, Roth N L. Explaining the limited effectiveness of legalistic "remedies" for trust/distrust [J]. Organization science, 1993, 4(3): 367-392.

[5] Park J, Lennon S.J. and Stoel L. On-line product presentation: Effects on mood perceived risk, and purchase intention [J]. Psychology and Marketing, 2005. 22(9): 695-719.

[6] Weiner B. Social motivation , justice and the moral emotions: An attributional approach [M]. 2005, Mahwah, NJ: Lawrence Erlbaum.

[7] Weiss A.M., E. Anderson and MacInnis D.J. Reputation management as a motivation for sales structure decisions [J]. Journal of Marketing, 1999. 64(4): 74-89.

[8] Westbrook R.A. and Oliver R.L. The dimensionality of consumption emotion patterns and consumer satisfaction [J]. Journal of consumer research, 1991. 18(1): 84-91.

[9] Peeters G. and Czapinski J. Positive-negative asymmetry in evaluations: The distinction between affective and informational negativity effects [J]. European review of social psychology, 1990. 1(1): 33-60.

[10] Peine K., Heitmann M. and Herrmann A. Getting a feel for price affect: A conceptual framework and empirical investigation of consumers' emotional responses to price information $[\mathrm{J}]$. Psychology and Marketing, 2009. 26(1): 39-66.

[11] Bearden W O, Teel J E. Selected determinants of consumer satisfaction and complaint reports [J]. Journal of Marketing Research, 1983, 20(1): 21-28.

[12] Pennings J.M.E., Wansink B. and Meulenberg M.T.G. A note on modeling consumer reactions to a crisis: The case of the mad cow disease [J]. International Journal of Research in Marketing , 2002. 19(1): 91-100. 